\title{
THE EFFECTS OF USING COMPLEX TRAINING METHOD ON MUSCULAR STRENGTH AMONG MALE WEIGHTLIFTERS
}

\author{
Wan Firdaus ${ }^{1}$, Garry Kuan ${ }^{2} \&$ Oleksandr Krasilshchikov ${ }^{3}$ \\ ${ }^{1}$ Faculty of Sports Science and Recreation, Universiti Teknologi MARA, \\ Kota Samarahan, Sarawak, Malaysia. \\ ${ }^{2}$ Sports Science Unit, School of Medical Sciences, Universiti Sains Malaysia, \\ Kota Bharu, Kelantan, Malaysia. \\ ${ }^{3}$ Exercise and Sports Science Programme, School of Health Sciences, Universiti Sains \\ Malaysia, Kota Bharu, Kelantan, Malaysia. \\ Email: firdaus085@sarawak.uitm.edu.my
}

\begin{abstract}
Journal of Sports Science and Physical Education 7(1): Received: 3 January 2018, Accepted: 10 February 2018 - Weightlifting is a sport that requires both dynamic strength and power. Until today, weightlifting coaches are still exploring different training modes in an attempt to enhance both muscular strength and power of the competitive weightlifters. Research has shown that the use of the "right" training method could further provide knowledge on such effect for competitive weightlifters (Storey \& Smith, 2012). Thus, the aim of this study was to investigate the effects of using the complex training method (applicable to weightlifting) compared to traditional resistance training on muscular strength among male competitive (state level) weightlifters. Seventeen male competitive weightlifters were randomly assigned into 2 groups: experimental group (Complex Training; $\mathrm{n}=9$ ), and control group (Traditional Resistance Training; $n=8$ ). All participants trained for 6 weeks ( 2 sessions per week) with the total training volume equated between both groups. Participants underwent pre-test and posttest including the anthropometric measurements (height, body weight, and body fat) and lower body strength (isokinetic strength test) parameters. The results showed that there was a significant increase from pre- to post-test in knee extension peak torque $\mathrm{t}(8)=-4.22 ; \mathrm{p}=.003$ and $\mathrm{t}(7)=-5.37 ; \mathrm{p}=.001$, and knee flexion peak torque $\mathrm{t}(8)=-5.98 ; \mathrm{p}=.001$ and $\mathrm{t}(7)=-4.20$; $\mathrm{p}=.004$ in experimental and control groups respectively. No significant difference $(\mathrm{p}>.05)$ was observed in knee extension peak torque $(22.9 \pm 16.3$ versus $13.9 \pm 7.3)$ and knee flexion peak torque $(11.4 \pm 5.7$ versus $10.1 \pm 6.8)$ improvements between the complex training group and control group respectively at post-test. In conclusion, the use of complex training method showed similar effects in enhancing muscular strength with traditional resistance training after 6 weeks of intervention.
\end{abstract}

Keywords: complex training, strength, weightlifting 


\section{INTRODUCTION}

Weightlifting is a sport that requires both dynamic strength and power (Storey \& Smith, 2012). It has been a longstanding part of the modern Olympic Games and has wide and growing intemational participation. Competitive weightlifting is divided into several body weight categories, which are different for men and women. For men, the body weights include $\leq 56 \mathrm{~kg}$, $\leq 62 \mathrm{~kg}, \leq 69 \mathrm{~kg}, \leq 77 \mathrm{~kg}, \leq 85 \mathrm{~kg}, \leq 94 \mathrm{~kg}, \leq 105 \mathrm{~kg}$, and $>105 \mathrm{~kg}$. As for women, the body weights include $\leq 48 \mathrm{~kg}, \leq 53 \mathrm{~kg}, \leq 58 \mathrm{~kg}, \leq 63 \mathrm{~kg}, \leq 69 \mathrm{~kg}, \leq 75 \mathrm{~kg}$, and $>75 \mathrm{~kg}$ (Storey \& Smith, 2012). Weightlifting involves with two multi-joint whole body lifts, performed during competition: "Snatch", and "Clean and Jerk" (CJ) (Storey \& Smith, 2012). The snatch requires the weighted barbell to be lifted from the floor using a wide grip to an overhead position in one continuous movement (International Weightlifting Federation, 2014). CJ, requires the barbell to be raised from the floor using a shoulder width grip to the front of the shoulders in one continuous movement followed by the barbell push the over the head (International Weightlifting Federation, 2014). During the performance of the two competitive lifts, the snatch and the CJ, weightlifters are required to generate extremely high peak forces and contractile rates of force development and, consequently, high peak power outputs and contractile impulses.

The training structure of a competitive weightlifter is characterised by the frequent use of high intensity resistance exercise movements. A weightlifter typically has two types of training that has been formulated specifically according to their competitive level - junior or senior. The first involves complementary exercises, which include movement patterns similar to the competitive lifts, such as hang snatch, power snatch, hang clean, power clean, snatch pull, clean pull, back squat, and front squat (Stone, Pierce, Sands, \& Stone, 2006). The second type of training is the supplementary exercises, which includes overhead presses, back extensions, and abdominal work (Storey \& Smith, 2012). Both types of training are known as resistance training. According to Storey and Smith (2012), many different coaching and training philosophies / methods exist for weightlifters, however much of these "methods" had not been scientifically documented, and thus further research is required to substantiate on the "best" training programme for men and women weightlifters of various age groups.

Complex training as a form of combined training is best described as training that alternates between traditional resistance (heavy resistance exercise) and plyometric exercises (light resistance exercise) within a single exercise session (Ebben \& Watts, 1998; Carter \& Greenwood, 2014). In complex training, the plyometrics performed will be biomechanically similar to the resistance movements performed immediately before those plyometric exercises The idea of using two biomechanically similar exercises performed together in a complex can be referred to as a complex pair (Saeed, 2013). Complex training may be an optimal training strategy for developing sport-specific athletic strength, if it is indeed true that this form of training is more effective than other training programs at enhancing strength (and possibly strength-power) production because of enhanced neuromuscular mechanisms (MacDonald, Lamont, \& Garner, 2012). Combining the bench press with medicine ball power drop is an example of upper body complex training (Chu, 1996). Similarly, for lower body complex training, it requires a combination of back squat and depth jumps (Ebben, 2002). The primary 
aim of complex training is to improve both strength and power on the same training session (Carter \& Greenwood, 2014).

Theoretically, complex training elicits properties of the neurological, muscular, and psychomotor systems to allow the individual to produce more power on the subsequent lighter set (Baker, 2003; Carter \& Greenwood, 2014). Specifically, complex training may stimulate motor unit excitability by increasing the motor unit recruitment, synchronisation, and the central input of a motor unit. Complex training may also increase phosphorylation of the myosin light chain in the muscle fibre, allowing the myofilaments to become more sensitive to calcium, decreasing the presynaptic inhibition, and subsequently increasing the power and strength output (Carter \& Greenwood, 2014; Hodgson, Dochery, \& Robbins, 2005). This response is referred to as postactivation potentiation (PAP) (Carter \& Greenwood, 2014; Hodgson, Dochery, \& Robbins, 2005).

According to MacDonald, Lamont, Garner, and Jackson (2013), complex training could promote gains in strength and power if the right recommendations during training were followed. For example, it could enhance the intensity, volume, exercise selection, and training frequency, leading to faster recovery. However, the intensity must be high enough on both resistance and plyometric training, and the volume must be low enough to prevent fatigue. Furthermore, the selection of the exercises must also be biomechanically similar. Typically, a proper complex training may be undertaken 1 to 3 times a week, with 48 to 96 hours of recovery inbetween (Chu, 1996; Ebben \& Watts, 1998). Despite the success of using complex training to enhance body stability and to increase body's strength, limited research has been conducted using complex training prescribed specifically for weightlifters. As complex training has been effectively proven in many sports such as volleyball (Saeed, 2013), gymnastics (Mohamed, 2011), rugby (Baker \& Newton, 2005), football (Hedrick \& Anderson, 1996), and baseball (Dodd \& Alvar, 2007), the use of complex training could potentially enhance the strength of the lower limb of the competitive weightlifters, and to increase their core stability, leading to the enhancement of weightlifting performance. Obviously, there is still much to be learned in relation to applying different intensity and duration of the complex training method, in particular for the weightlifters. Therefore, the objective of this study is to examine the effects of complex training (applicable to weightlifting) compared to traditional weightlifting resistance training on muscular strength of the male competitive weightlifters. This research is designed to compare whether a newly developed exercise programme (complex training) is more effective to enhance the strength of the weightlifter compared to the traditional resistance training method, which has been used for most weightlifting's training regime. The findings will enhance our knowledge on either beneficial or detrimental effects from using the complex training method. The results of this study can be used by coaches, conditioning trainers, fitness instructors and also athletes in their respective sports in an attempt to use this training method for enhancing muscle strength. 


\section{METHODS}

\section{Perticipants}

Seventeen healthy male competitive state level weightlifters volunteered to participate in this study. All participants had at least 2 years of competitive weightlifting experience at the state level. They were invited to participate by using a poster attached to the notice board at the weightlifting training venue. Their age ranged from 15 to 22 years old (mean age $15.7 \pm 0.93$ years). Participants were randomly selected using computer generated randomised control trial and were assigned to the experimental group (complex training) and the control group (traditional resistance training) randomly. Participants were informed that they were free to withdraw from the study at any time and signed the consent form if they wished to participate in this study. Participants were informed that the results would be confidential. All participants in this study were free from health problems and medical conditions.

\section{Testing Procedures}

Participants were tested before and after 6 weeks of intervention. Tests were precluded with a general warm-up and stretching.

Height. Participants' height was measured without shoes with participant stood straight with eyes looking straight forward and participant's feet flat on the portable stadiometer and close together. Height was measured to the nearest $0.1 \mathrm{~cm}$.

Body weight. Participants' body weight was also measured without shoes and with minimal clothing. The participants stood straight and steady on the body composition analyser and the body weight was measured to the nearest $0.1 \mathrm{~kg}$.

Body fat. Body fat was measured without shoes and heavy clothing with the participant standing straight and static on the body composition analyser. The body fat was measured to the nearest $0.1 \%$.

Isokinetic Strength Test. To undergo an isokinetic strength test, Participant performed a general cardiovascular warm up for at least five minutes on a Monark cycle ergometer at a moderate pace $(50-100 \mathrm{~W})$ followed by ten minutes of dynamic stretching such as walking lunges and squats involving the lower body (Hadzic, Sattler, Markovic, Veselko, \& Dervisevic, 2010). Then, participant was seated on the chair and assumed his/her most comfortable position to perform the tests. Participant was secured with snug straps across the shoulders, chest and hip. The cuff of the dynamometer's lever arm was attached proximally to the malleoli of the ankle. Dynamometer orientation was fixed at $90^{\circ}$ and tilted at $0^{\circ}$, while the seat orientation was fixed at $90^{\circ}$ and the seat back tilted at $70^{\circ}-85^{\circ}$ (Daneshjoo, Mokhtar, Rahnama, \& Yusof, 2013). The lateral epicondyle of the knee was visually aligned with the dynamometer rotational axis. The participant then performed concentric knee extension and flexion five times at angular 
velocity $60^{\circ} . \mathrm{s}^{-1}$ with five seconds rest intervals in between. A three minutes break was taken when the machine setting was changed for the opposite leg. The net peak torque values were recorded and used for data analysis.

\section{Intervention}

This is a pre-test - intervention - post-test design study to investigate the effects of complex training compared to traditional resistance training on muscular strength of the competitive weightlifters. Ethical approval was obtained from the Human Research Ethics Committee of the authors' institution (USM/JEPeM/1406232), and the study followed the recommendation by the Declaration of Helsinki and the guidelines of good clinical practice (GCP). Necessary permissions were obtained prior to the study using standard consent procedures. After recruiting the participants, the participants were randomly divided into two groups using computerised generated randomised control trial. The experimental group (complex training group) followed the complex training protocol, and the control group (traditional resistance training group) followed the traditional resistance training protocol. The total training volume was equated between complex training and traditional resistance training groups. Duration of intervention was 6 weeks (MacDonald, Lamont, \& Garner, 2012). Participants only required to train 2 times per week $(3.00 \mathrm{pm}-5.00 \mathrm{pm})$ on Sunday and Wednesday. Testings were conducted prior to intervention and after 6 weeks of intervention. Finally, participants were debriefed participants and thanked for their participation.

\section{Data and Statistical Analysis}

Statistical analysis was performed using the Statistical Package for Social Sciences (SPSS) version 22. All data were examined for normality through the Kolmogrov-Smirnov test. Descriptive statistics (mean and standard deviation) were used to describe the study variables. Preliminary analysis using the independent $t$-test was used to examine any differences between two groups on the baseline. Paired Sample $t$-test was performed to measure significant differences within the groups. Then, Independent $t$-test was used to see the difference between the groups. Statistical significance was accepted at $\mathrm{p}<.05$. In the independent $t$-test, the results were checked using the Levene's test to test the equality of variance.

\section{RESULTS}

\section{Lower Body Strength}

Preliminary analysis on the baseline showed no significant difference in knee extension peak torque $(p=0.67)$ and knee flexion peak torque $(p=0.26)$ between complex training group and traditional resistance training group. Based on the results at Table 1, there was a significant increase in knee extension peak torque $(t=-4.22 ; \mathrm{df}=8 ; p=0.003)$ and knee flexion peak torque $(t=-5.98 ; \mathrm{df}=8 ; p=0.001)$ from pre-test to post-test for the complex training group. 
The results from Table 1 also showed there was a significant increase in knee extension peak torque $(t=-5.37 ; \mathrm{df}=7 ; p=0.001)$ and knee flexion peak torque $(t=-4.20 ; \mathrm{df}=7 ; p=0.004)$ from pre-test to post-test also found for the traditional resistance training group.

Table 1 Paired Sample $t$-test Result for Knee Peak Torque (Nm)

\begin{tabular}{lcc}
\hline Knee Peak Torque (Nm) & $\begin{array}{c}\text { Complex } \\
\text { Training Group }(\boldsymbol{n}=\mathbf{9})\end{array}$ & $\begin{array}{c}\text { Traditional Resistance } \\
\text { Training Group }(\boldsymbol{n}=\mathbf{8})\end{array}$ \\
\hline Knee Extension $(\mathbf{N m})$ & $180.5 \pm 40.4$ & $190.2 \pm 52.1$ \\
Pre-test & $203.5 \pm 52.3$ & $204.1 \pm 52.9$ \\
Post-test & 0.003 & 0.001 \\
$p$ Value & & \\
Knee Flexion (Nm) & $75.1 \pm 15.9$ & $85.7 \pm 21.4$ \\
Pre-test & $86.6 \pm 18.9$ & $95.8 \pm 20.4$ \\
Post-test & 0.001 & 0.004 \\
$p$ Value & & \\
\hline
\end{tabular}

Table 2 showed the results of knee extension peak torque using the Independent sample $t$-test for both intervention groups. The mean knee extension peak torque increased from pretest to post-test for the complex training group $(22.9 \pm 16.3 \mathrm{Nm})$, compared to traditional resistance training group $(13.9 \pm 7.3 \mathrm{Nm})$. However, Independent sample $t$-test showed that there was no significant difference in knee extension peak torque between complex training group and traditional resistance training group after the 6 weeks intervention, $t(15)=1.44, p=$ 0.17 . Table 2 showed the results of the knee flexion peak torque. The mean knee flexion peak torque increased from pre-test to post-test for complex training group $(11.4 \pm 5.7 \mathrm{Nm})$, compared to traditional resistance training group $(10.1 \pm 6.8 \mathrm{Nm})$. However, Independent Sample $t$-test also showed that there was no significant difference in knee flexion peak torque between complex training group and traditional resistance training group after the 6 weeks of intervention, $t(15)=0.42, p=0.68$.

Table 2 Independent Sample $t$-test Result for Knee Peak Torque (Nm)

\begin{tabular}{lcccccc}
\hline & N & Mean & SD & df & $\boldsymbol{t}$ & $\boldsymbol{p}$ \\
\hline Knee Extension Peak Torque (Nm) & & & & & & \\
$\quad$ Complex Training Group & 9 & 22.9 & 16.3 & 15 & 1.44 & 0.17 \\
$\quad$ Traditional Resistance Training Group & 8 & 13.9 & 7.3 & & & \\
$\quad$ Knee Flexion Peak Torque (Nm) & & & & & & \\
$\quad$ Complex Training Group & 9 & 11.4 & 5.7 & 15 & 0.42 & 0.68 \\
$\quad$ Traditional Resistance Training Group & 8 & 10.1 & 6.8 & & & \\
\hline
\end{tabular}

\section{DISCUSSION}

The findings from the present study showed that there were significant increases in knee extension peak torque and knee flexion peak torque from pre-test to post-test for both groups (complex training group and traditional resistance training group). The increase occurred 
because both training programmes (complex training and traditional resistence training) were suitable training methods for improving muscular strength. Strength gains occuring during the first 4-8 weeks of training are primarily attributed to neural adaptations marked by the increase in integrated electromyographic (IEMG) activity, the increase in the rate of motor unit activity as well as the increase in motor unit synchronisation (Szymanski, Szymanski, Molloy, \& Pascoe, 2004). Previous studies related to complex training stated that complex training could promote gains in strength if the right recommendations during training were followed such as the intensity, volume, specificity, exercise selection, training frequency, and recovery (Chu, 1996; Comyns, Hennessy, \& Jensen, 2006; Deutsch \& Lloyd, 2008; Ebben \& Watts, 1998; MacDonald, Lamont, \& Garner, 2012). A study conducted by Mohamed (2011) found that complex training significantly improved the static and dynamic strength in gymnasts. Similar study conducted by Saeed (2013) also found that complex training significantly improved the lower body strength among volleyball players. Research related to weightlifting also found that weightlifting training (traditional resistance training) in moderate volume of high relative training produced greater strength gains compared with low and high volume (GonzalezBadillo, Izquierdo, \& Gorostiaga, 2006). A similar study by Gonzalez-Badillo, Izquierdo, and Gorostiaga (2005) found that weightlifting training (traditional resistance training) in moderate resistance training volume produced more favourable strength gains than high or low volume during a short term training cycle. Otto, Coburn, Brown, and Spiering (2012) in their study of 6 weeks intervention found that weightlifting training induced significantly greater improvement in strength compared with Kettlebell training.

Despite having significant increase in knee extension peak torque and knee flexion peak torque from pre-test to post-test for both groups, the present study showed no significant difference in knee extension peak torque and knee flexion peak torque between complex training group and traditional resistance training group after the 6 week intervention. This is due to both training methods were suitable for improving muscular strength. Present result was supported by the study from Carter and Greenwood (2004) which found that complex training significantly increased the dynamic strength and improved the explosive strength in comparable magnitude of changes to resistance and plyometric training programs in track and field athletes. Similarly, a study conducted by Robbins, Young, Behm, and Payne (2009) also found no significant difference in strength between complex training and traditional resistance training after 8 weeks intervention among recreational trained persons. In addition, MacDonald, Lamont, Garner, and Jackson (2013) also found no significant difference in strength between complex training, plyometric training, traditional resistance training after the 6 weeks intervention among recreational trained college students. When looking at the mean gains in the knee extension peak torque and knee flexion peak torque; mean gains in knee extension peak torque and knee flexion peak torque after complex training were higher than mean gains in knee extension peak torque and knee flexion peak torque after traditional resistance training. This could be because of the highly induced factor of fatigue in complex training, which might act as a stimulus that led to eventual increase in strength. This is because complex training combines high load resistance and plyometric training. Rooney, Herbert, and Balnave (1994) suggested that training protocols that produce more fatigue might result in greater motor unit activation that non-fatiguing, and that the level of motor unit activation 
determines the magnitude of the training response. This is because the greater the time difference between the conditioning activity and subsequent performance, the greater the recovery from fatigue, but also the greater the decrement in PAP (Jeffreys, 2008).

From the results of the present study, we found that there were significant increases in knee extension peak torque and knee flexion peak torque from pre-test to post test for both groups but not significantly different in term of increasing the knee extension peak torque and knee flexion peak torque between complex training group and traditional resistance training group after the 6 weeks of intervention. This showed that both training programmes are effective in increasing the knee extension peak torque and knee flexion peak torque of the weightlifters.

\section{Conclusion}

The findings of this study showed significant increase in knee extension peak torque and knee flexion peak torque from pre-test to post test for both intervention groups. But, there are no significant differences in knee extension peak torque and knee flexion peak torque found between complex training group and traditional training group after 6 weeks of intervention. This indicated that both training methods resulted in similar improvements in knee extension peak torque and knee flexion peak torque. In conclusion, complex training has similar improvements in muscular strength with the traditional resistance training.

\section{Acknowledgement}

This research is supported by the USM Short Term Grant (304/PPSP/61313041).

\section{References}

Adam, G. M. (2002). Exercise Physiology: Laboratory Manual (Fourth Edition ed.). New York: McGraw-Hill.

Adams, K., O'Shea, J. P., O'Shea, K. L., \& Climstein, M. (1992). The effect of six weeks of squat, plyometric and squat-plyometric training power production. Journal Applied Sports Science Research, 6 (1), 36-41.

Arabatzi, F., \& Kellis, E. (2012). Olympic weightlifting training causes different knee muscle coactivation adaptations compared with traditional weight training. Journal of Strength and Conditioning Research, 26 (8), 2192-2201.

Baker, D. (2003). Acute effect of alternating heavy and light resistance on power output during upper body complex power training. Strength and Conditioning Journal, 17, 493-497.

Baker, D., \& Newton, R. U. (2005). Acute effect on power output of alternating an agonist and antagonist muscle exercise during complex training. Journal of Strength and Conditioning Research, 19, 202-205.

Bompa, T. O. (1999). Theory and methodology of training. United States: Human Kinetics. 
Brown, S. R., Brughelli, M., Griffiths, P. C., \& Cronin, J. B. (2014). Lower Extremity Isokinetic Strength Profiling in Professional Rugby League and Rugby Union. International Journal of Sports Physiology and Performance, 9, 358-361.

Burger, T., Boyer-Kendrick, T., \& Dolny, D. (2000). Complex training compared to a combined weight training and plyometric training program. Journal of Strength and Conditioning Research, 14 (3), 360 .

Carter, J., \& Greenwood, M. (2014). Complex Training Reexamined: Review and Recommendations to Improve Strength and Power. Strength and Conditioning Journal, 36 (2), 11-19.

Cavaco, B., Sousa, N., Reis, V. M., Garrido, N., Saavedra, F., Mendes, R., et al. (2014). Short-term effects of complex training on agility with the ball, speed, efficiency of crossing and shooting in youth soccer players. Journal of Human Kinetics, 43 (1), 105-112.

Chaouachi, A., Hammami, R., Kaabi, S., Chamari, K., Drinkwater, E. J., \& Behm, D. G. (2014). Olympic weightlifting and plyometric training with children provider similar or greater performance improvements than traditional resistance training. Journal Strength and Conditioning Research, 28 (6), 1483-1496.

Chiu, L. Z., Fry, A. C., Weiss, L. W., Schilling, B. K., Brown, L. E., \& Smith, S. L. (2003). Post activation potentiation response in athletic and recreationally trained individuals. Journal of Strength and Conditioning Research, 17, 671-677.

Chu, D. A. (1996). Explosive Power and Strength: Complex Training for Maximum Results. California: Human Kinetics.

Coffey, V., Reeder, D., \& Lancaster, G. (2007). Effect of high frequency resistance exercise on adaptive responses in skeletal muscle. Medicine Science Sports Exercise, 39 (12), 2135-2144.

Comyns, T. M., Harrison, A. J., Hennessy, L. K., \& Jensen, R. L. (2006). The optimal complex training rest interval for athletes from anaerobic sports. Journal of Strength and Conditioning Research, 20, 471-476.

Comyns, T. M., Harrison, A. J., Hennessy, L., \& Jensen, R. L. (2007). Indentifying the optimal resistive load for complex training in male rugby players. Sports Biomechanics, 6 (1), 59-70.

Crewther , B., \& Christian, C. (2010). Relationships between salivary testosterone and cortisol concentration and training performance in Olympic weightlifters. Journal Sports Medicine Physical Fitness, 50 (3), 371-375.

Daneshjoo, A., Mokhtar, A., Rahnama, N., \& Yusof, A. (2013). The Effects of Injury Prevention Warm Up Programmes on Knee Strength in Male Soccer Players. Biology of Sport, 30 (4), 281-288.

Deutsch, M., \& Lloyd, R. (2008). Effect of order of exercise on performance during a complex training session in rugby players. Journal of Sports Sciences, 26 (8), 803-809.

Docherty, D., Robbins, D., \& Hodgson, M. (2004). Complex Training revisited: a review of its current status as a viable training approach. Strength and Conditioning Journal, 26, 52-57.

Dodd, D. J., \& Alvar, B. A. (2007). Analysis of acute explosive training modalities to improve lower body power in baseball players. Journal of Strength and Conditioning Research, 21, 11771182.

Duthie, G. M., Young, W. B., \& Aitken, D. A. (2002). The acute effects of heavy loads on jump squat performance: An evaluation of the complex and contrast methods of power development. Journal Strength and Conditioning Research, 16, 530-538.

Ebben, W. P., \& Blackard, D. O. (1997). Developing a strength power program for amatuer boxing. Strength and Conditioning Research, 19 (1), 42-51.

Ebben, W. P., \& Watts, P. B. (1998). A Review of Combined Weight Training and Plyometric Training Modes: Complex Training. Strength and Conditioning Journal, 20, 18-27. 
Ebben, William P. (2002). Complex Training: A Brief Review. Journal of Sports Science and Medicine, $1,42-46$.

Fleck, \& Kraemer. (1997). Designing Resistance Training Programs. Chicago: Human Kinetics.

Gabbett, T., Kelly, J., \& Pezet, T. (2008). A comparison of fitness and skill among playing positions in sub-elite rugby league players. Journal of Strength and Conditioning Research, 11 (6), 585592.

Garhammer, J. (1980). Power production by Olympic weightlifters. Medicine Science Sports Exercise, $12(1), 54-60$.

Gennuso, K. P., Zalewski, K., Cashin, S. E., \& Strath, S. J. (2013). Resistance Training Congruent With Minimal Guidelines Improves Function in Older Adults: A Pilot Study. Journal of Physical Activity and Health, 10 (6), 769-776.

Gomez, J. P., Olmedillas, H., Guerra, S. D., Royo, I. A., Rodriquez, G. V., Ortiz, R. A., et al. (2008). Effects of weight lifting training combined with plyometric exercises on physical fitness, body composition and knee extension velocity during kicking football. Journal of Applied Physiology Nutrition Metabolism, 33 (3), 501-510.

Gonzalez-Badillo, J. J., Gorostiaga, E. M., Arellano, R., \& Izquierdo, M. (2005). Moderate resistance training volume produces more favorable strength gains than high or low volumes during a short term training cycle. Journal Strength and Conditioning Research, 19 (3), 689-697.

Gonzalez-Badillo, J. J., Izquierdo, M., \& Gorostiaga, E. M. (2006). Moderate volume of high relative training intensity produces greater strength gains compared with low and high volumes in competitive weightlifter. Journal of Strength and Conditioning Research, 20 (1), 73-81.

Gould, D., Eklund , R. C., \& Jackson, S. A. (1992b). 1988 U.S Olympic wrestling excellence: II. Thoughts and affect occurring during competition. The Sport Psychologist, 6, 383-402.

Gould, D. E. (1992a). 1988 U.S Olympic wrestling excellence: I. Mental preparation, precompetitive cognition, and affect. The Sport Psychologist, 6, 368-382.

Hadzic, V., Sattler, T., Markovic, G., Veselko, M., \& Dervisevic, E. (2010). The isokinetic strength profile of quadriceps and hamstrings in elite volleyball players. Journal of Exercise Science, 18 (1), 31-37.

Hakkinen, K., Pakarinen, A., \& Alen, M. (1988). Neuromuscular and hormonal adaptations in athletes to strength training in two years. Journal Applied Physiology, 65 (6), 2406-2412.

Hanton, S., \& Jones, G. (1999). The acquisition and development of cognitive skills and strategies: Making the butterflies fly in formation. The Sport Psychologist, 13, 1-21.

Hedrick, A. (1994). Strength and power training for the national speed skating team. Journal of Strength and Conditioning Research, 16 (5), 33-39.

Hedrick, A., \& Anderson, J. C. (1996). A review of the literature and a team case study. Journal Strength and Conditioning Research, 4, 7-12.

Hodgson, M., Dochery, D., \& Robbins, D. (2005). Post-activation potentiation: Underlying physiology and implications for motor performance. Sports Medicine, 35 (7), 585-595.

Hori, N., Newton, R. U., Nosaka, K., \& Stone, M. H. (2005). Weightlifting exercises enhance athletic performance that requires high-load speed strength. National Strength and Conditioning Research, 27 (4), 50-55.

Ignjatovic, A. M., Markovic, Z. M., \& Radovanovic, D. S. (2012). Effects of 12 weeks medicine ball training on muscle strength and power in young female handball players. Journal of Strength and Conditioning Research, 26 (8), 2166-2173.

Jackson, R. C., \& Baker, J. S. (2001). Routines, rituals, and rugby: Case study of a world class goal kicker. The Sport Psychologist, 15, 48-65. 
Janz, J., Dietz, C., \& Malone, M. (2008). Training Explosiveness: Weightlifting and Beyond. Journal of Strength and Conditioning Research, 30 (6), 14-22.

Jastrzebski, Z., Mikolajewski, R., Radziminski, L., Wnorowski, K., \& Jaskulska, E. (2014). The effect of a 6 week plyometric training on explosive power in volleyball players. Baltic Journal of Health and Physical Activity, 6 (2), 79-89.

Jeffreys, I. (2008, December). A review of post activation potentiation and its application in strength and conditioning. UK Strength and Conditioning Association, 12, 17-25.

Komi, P., \& Bosco, C. (1978). Utilization of stored elastic energy in leg extensor muscles by men and women. Journal of Medicine Science Sports, 10 (4), 261-265.

Lategan, L. (2012). Comparison of isokinetic knee flexion and extension between men and women. African Journal for Physical, Health Education, Recreation and Dance, 18 (4), 841-851.

MacDonald, C. J., Lamont, H. S., \& Garner, J. C. (2012). A comparison of the effects of 6 weeks of traditional resistance training, plyometric training and complex training on measures of strength and anthropometrics. Journal of Strength and Conditioning Research, 26 (2), 422-431.

MacDonald, C. J., Lamont, H. S., Garner, J. C., \& Jackson, K. (2013). A comparison of the effects of six weeks of traditional resistance training, plyometric training and complex training in measured of power. Journal of Trainology, 2, 13-18.

Matthews, M., \& Comfort, P. (2008). Applying complex training principles to boxing: A practical approach. Strength and Conditioning Journal, 30 (5), 12-15.

McBride, J. M., Triplett-McBride, T., Davie, A., \& Newton, R. U. (1999). A comparison of strength and power characteristics between power lifters, olympic lifters, and sprinters. Journal Strength and Conditioning Research, 7, 58-66.

Mohamed, G. A. (2011). Effects of complex training on certain physical variables and performance level of landing in floor exercise. Journal of Science, Movement and Health, 11 (2), 171-175.

Naso, J. D., Pritschet, B. L., Emmett, J. D., Owen, J. D., Willardson, J. M., Beck, T. W., et al. (2012). Comparing thigh muscle cross-sectional area and squat strength among national class olympic weightlifter, powerlifters and bodybuilders. International Sports Medicine Journal, 13 (2), 4857.

Otto, W. H., Coburn, J. W., Brown, L. E., \& Spiering, B. A. (2012). Effects of weightlifting vs. kettlebell training on vertical jump, strength and body composition. Journal of Strength and Conditioning Research, 26 (5), 1199-1202.

Ozen, S. V. (2012). Reproductive Hormones and Cortisol Responses to Plyometric Training in Males. Biology of Sports, 29, 193-197.

Patton, M. Q. (2002). Qualitative evaluation and research methods (3rd ed). CA: Sage Publications.

Pearson, S. J., Young, A., \& Macaluso, A. (2002). Muscle function in elite master weightlifters. Medicine Science Sports Exercise, 34 (7), 1199-1206.

Poletaev, P., Cervera, V., \& Coach, W. (1995). The Russian approach to planning a weightlifting program. Strength and Conditioning Research, 24 (3), 20-26.

Retrieved October 15, 2014, from International Weightlifting Federation: www.iwf.net/weightlifitng_/the-two-lifts/

Robbins, D. W., Young, W. B., Behm, D. G., \& Payne, W. R. (2009). Effects of agonist-antagonist complex resistance training on upper body strength and power development. Journal of Sports Sciences, 27 (14), 1617-1627.

Rooney, K. J., Herbert, R. D., \& Balnave, R. J. (1994). Fatigue contirbutes to the strength training stimulus. Journal of Medicine and Science in Sports and Exercise, 26 (9), 1160-1164.

Saeed, K. K. (2013). Effect of Complex Training with low-intensity loading interval on certain physical variables among volleyball infants (10-12 ages). Science, Movement and Health, 13 (1), 16-21. 
Santos, E., \& Janeir, M. (2008). Effects of complex training on explosive strength in adolescent male basketball players. Journal Strength and Conditioning Research, 22, 903-909.

Sheehan, K. (2010, October 10). Retrieved October 19, 2014, from LIVESTRONG.COM: www.livestrong.com/article/275029-the-history-of-weightlifting/\#page=3.

Stone, M. H., Pierce, K. C., Sands, W. A., \& Stone, M. E. (2006). Weightlifting: Program Design. National Strength and Conditioning Journal, 28 (2), 10-17.

Stone, M. H., Sands, W. A., Pierce, K. C., Ramsey, M. W., \& Haff, G. G. (2008). Power and power potentiation among strength power athletes: Preliminary Study. International Journal Sports Physiology Performance, 3 (1), 55-67.

Storey, A., \& Smith, H. K. (2012). Unique Aspects of Competitive Weightlifting. Sports Medicine, 42 (9), 769-790.

Szymanski, D. J., Szymanski, J. M., Molloy, J. M., \& Pascoe, D. D. (2004). Effects of 12 weeks of wrist and forearm training on high school baseball players. Journal Strength and Conditioning Research, 18 (3), 432-440.

Tricoli, V., Lamas, L., Carnevale, R., \& Ugrinowitsch, C. (2005). Short Term Effects on Lower Body Functional Power Development: Weightlifting vs Vertical Jump Training Programs. Journal of Strength and Conditioning Research, 19 (2), 433-437.

Verkhoshansky, Y. (1986). Speed strength preparation and development of strength endurance of athletes in various specializations. Soviet Sports Review, 11 (6), 120-124.

Young, W. B., Jenner, A., \& Griffiths, K. (1998). Acute enhancement of power performance from heavy load squats. Journal Strength and Conditioning Research, 12 (2), 82-84.

Zatsiorsky, \& Vladimir, M. (1995). Science and Practice of Strength Training. Chicago: Human Kinetics.

Zatsiorsky, V. M. (1992). International perspective: intensity of strength training facts and theory. Russian and Eastern European approach. Journal Strength and Conditioning, 14 (5), 46-57.

\section{Đ- Wan Firdaus}

Faculty of Sports Science and Recreation, Universiti Teknologi MARA,

Kota Samarahan, Sarawak

Malaysia 